\title{
The case of the disappearing teaspoons: longitudinal cohort study of the displacement of teaspoons in an Australian research institute
}

\author{
Megan S C Lim, Margaret E Hellard, Campbell K Aitken
}

Centre for

Epidemiology and

Population Health

Research,

Macfarlane Burnet

Institute for Medical

Research and

Public Health,

GPO box 2284 ,

Melbourne,

Victoria, 3001

Australia

Megan S C Lim

research assistant

Margaret E Hellard

director

Campbell K Aitken

senior research officer

Correspondence to:

C K Aitken

aitken@burnet.edu.au

BMJ 2005;331:1498-500

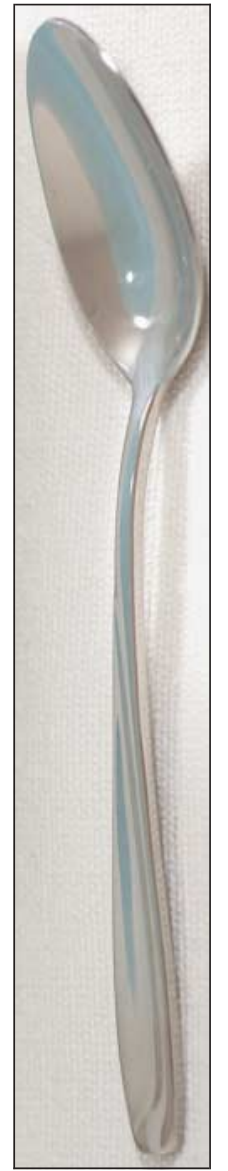

\begin{abstract}
Objectives To determine the overall rate of loss of workplace teaspoons and whether attrition and displacement are correlated with the relative value of the teaspoons or type of tearoom.

Design Longitudinal cohort study.

Setting Research institute employing about 140 people.

Subjects 70 discreetly numbered teaspoons placed in tearooms around the institute and observed weekly over five months.
\end{abstract}

Main outcome measures Incidence of teaspoon loss per 100 teaspoon years and teaspoon half life.

Results $56(80 \%)$ of the 70 teaspoons disappeared during the study. The half life of the teaspoons was 81 days. The half life of teaspoons in communal tearooms (42 days) was significantly shorter than for those in rooms associated with particular research groups (77 days). The rate of loss was not influenced by the teaspoons' value. The incidence of teaspoon loss over the period of observation was 360.62 per 100 teaspoon years. At this rate, an estimated 250 teaspoons would need to be purchased annually to maintain a practical institute-wide population of 70 teaspoons.

Conclusions The loss of workplace teaspoons was rapid, showing that their availability, and hence office culture in general, is constantly threatened.

\section{Introduction}

In January 2004 the authors found their tearoom bereft of teaspoons. Although a flunky (MSCL) was rapidly dispatched to purchase a new batch, these replacements in turn disappeared within a few months. Exasperated by our consequent inability to stir in our sugar and to accurately dispense instant coffee, we decided to respond in time honoured epidemiologists' fashion and measure the phenomenon.

A search of the medical and other scientific literature through Google, Google Scholar, and Medline using the keywords "teaspoon", "spoon", "workplace", "loss" and "attrition" revealed nothing about the phenomenon of teaspoon loss. Lacking any guidance from previous researchers, we set out to answer the age old question "Where have all the bloody teaspoons gone?" We aimed to determine the overall rate of loss of teaspoons and the half life of teaspoons in our institute, whether teaspoons placed in communal tearooms were lost at a different rate from teaspoons placed in individual tearooms, and whether better quality teaspoons would be more attractive to spoon shifters or be more highly valued and respected and therefore move and disappear more slowly.

\section{Methods}

The Macfarlane Burnet Institute for Medical Research and Public Health (Burnet Institute) based in Melbourne, employs about 140 people. The institute has eight tearooms; four are "programme linked"-that is, predominantly used by the staff of a single programme-and four are communal: two are attached to formal meeting rooms, one is a large multipurpose staff room, and one is a rather barren corridor with kitchen facilities.

\section{Pilot study}

Between 5 February 2004 and 18 June 2004 we carried out a pilot study to gain an initial impression of the manner of teaspoon loss at the institute and to refine our methods for the full study. We purchased 32 plain stainless steel teaspoons, discreetly numbered with red nail polish on the undersides of the handles, and distributed into a subset of the eight tearooms: 16 in the programme linked tearooms and 16 in the communal tearooms. We carried out a weekly audit over five months to assess any changes in the distribution of the teaspoons throughout the institute.

\section{Main study}

At the completion of the pilot study we carried out a longitudinal cohort study. We purchased and numbered a further 54 stainless steel teaspoons. In addition we purchased and discreetly numbered 16 teaspoons of higher quality. The teaspoons were distributed (stratified by spoon type) throughout the eight tearooms, with a higher proportion allocated to those tearooms with the highest teaspoon losses in the pilot study.

We carried out counts of the teaspoons weekly for two months then fortnightly for a further three months. Desktops and other immediately visible surfaces were scanned for errant spoons.

After five months we revealed our previously covert research project to the institute's staff. They were asked to return or anonymously report any marked teaspoons that had made their way into desk drawers or homes. Two days after the revelation, staff were asked to complete a brief anonymous questionnaire, which dealt with their attitudes towards and knowledge of teaspoons and teaspoon theft.

Details of the statistical analysis and study limitations are on bmi.com 


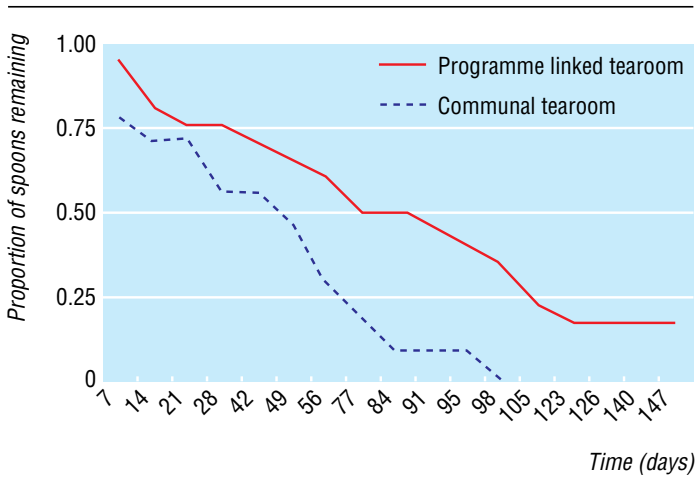

Fig 1 Proportion of teaspoons remaining by final tearoom type

\section{Results}

After five months, 56 (80\%) of 70 teaspoons had disappeared. The half life of the teaspoons was 81 days (that is, half had disappeared permanently after that time) compared with 63 days in the pilot study. The type of tearoom in which spoons were initially placed did affect the rate of loss. The amount of time a teaspoon survived in its final room did, however, vary significantly according to final tearoom type: half life 42 days for communal rooms (observed 28, expected 20.5) and 77 days for programme linked rooms (observed 57, expected 64.5, $\mathrm{P}<0.05$; fig 1 ). The rate of loss of the higher quality teaspoons (observed 12, expected 12.4) was not significantly different to that of standard quality teaspoons (observed 44, expected 43.6, $\mathrm{P}=0.88$; fig 2).

We observed the teaspoons for a total of 5668 teaspoon days. The rate of teaspoon loss over the period of observation was 0.99 per 100 teaspoon days (95\% confidence interval 0.76 to 1.28 ), or 360.62 per 100 teaspoon years. Assuming an average daily population of 140 people in the institute, this translates to a rate of loss of 2.58 teaspoons per person per 100 teaspoon years. Therefore to maintain a workable population (one spoon for every two people) 252.4 (194.3 to 328 ) teaspoons would need be purchased every year.

If we assume that the annual rate of teaspoon loss per employee can be applied to the entire workforce of the city of Melbourne (about 2.5 million), an estimated 18 million teaspoons are going missing in Melbourne each year. Laid end to end, these lost teaspoons would

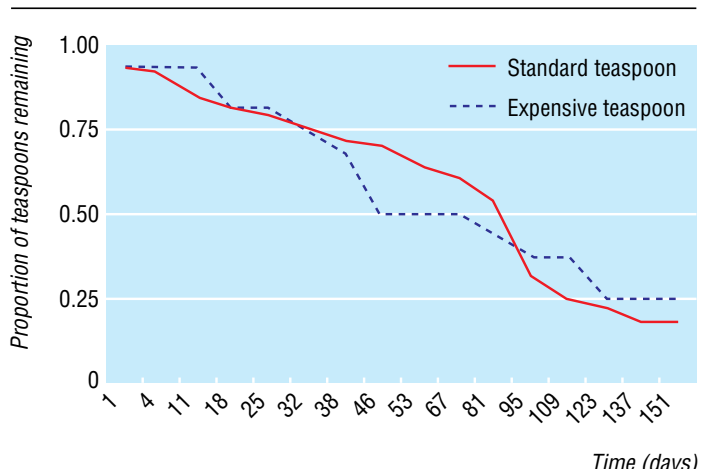

Fig 2 Proportion of teaspoons remaining by teaspoon type

\section{Results of follow-up teaspoon questionnaire}

\begin{tabular}{|c|c|}
\hline Questions and possible answers & $\begin{array}{c}\text { No }(\%) \text { of responses } \\
(n=94)\end{array}$ \\
\hline \multicolumn{2}{|l|}{ Have you ever stolen a teaspoon? } \\
\hline Yes & $36(38)$ \\
\hline No & $58(62)$ \\
\hline \multicolumn{2}{|l|}{ If yes, from where?* } \\
\hline Work & $22(61)$ \\
\hline School or university & $11(31)$ \\
\hline Home of a friend or relative & $13(36)$ \\
\hline Shop or store & $6(17)$ \\
\hline Pub or restaurant & $10(28)$ \\
\hline Aeroplane & $4(11)$ \\
\hline \multicolumn{2}{|c|}{ Have you stolen a teaspoon in the past year? } \\
\hline Yes & $18(19)$ \\
\hline No & $76(81)$ \\
\hline \multicolumn{2}{|l|}{ If yes, from where?* } \\
\hline Work & $10(56)$ \\
\hline School or university & $5(28)$ \\
\hline Home of a friend or relative & $9(50)$ \\
\hline Shop or store & $4(22)$ \\
\hline Pub or restaurant & $6(33)$ \\
\hline Aeroplane & $2(11)$ \\
\hline \multicolumn{2}{|l|}{ Stealing teaspoons is wrong: } \\
\hline Strongly agree & $31(33)$ \\
\hline Agree & $23(24)$ \\
\hline Unsure & $15(16)$ \\
\hline Disagree & $13(14)$ \\
\hline Strongly disagree & $12(13)$ \\
\hline \multicolumn{2}{|c|}{ How satisfied are you with teaspoon coverage in the institute? } \\
\hline Very satisfied & $0(0)$ \\
\hline Satisfied & $6(6)$ \\
\hline Unsure & $19(20)$ \\
\hline Dissatisfied & $17(18)$ \\
\hline Very dissatisfied & $52(55)$ \\
\hline
\end{tabular}

*Multiple answers possible.

cover over $2700 \mathrm{~km}$ - the length of the entire coastline of Mozambique ${ }^{1}$-and weigh over 360 metric tons-the approximate weight of four adult blue whales. ${ }^{2}$

After the revelation of the study to the institute's staff, five potentially lost teaspoons were recovered from miscreant hoarders. Four of these were returned from areas far removed from their place of last observation; one had been missing for 20 weeks. No one admitted to the permanent removal of a teaspoon from the institute, and no plausible explanations were advanced for the high rate of teaspoon loss.

\section{Follow-up questionnaire}

Overall, 94 employees (response rate 67\%) responded to the follow-up questionnaire. Thirty six $(38 \%)$ were male, 57 were female $(61 \%)$, and one was undecided. The table shows selected results.

\section{Discussion}

Displacement of teaspoons outside tearooms at the Burnet Institute, Australia, was highly efficient, at the rate of nearly one teaspoon lost per 100 teaspoon days. Despite the purchase of substantial numbers of replacement teaspoons during the study period, most employees $(73 \%)$ remained dissatisfied with teaspoon coverage in the institute. 
Although the scientific literature is strangely bereft of teaspoon related research, the phenomena we have described are capable of interpretation using some well known theoretical perspectives. For example, in his classic essay The tragedy of the commons, ${ }^{3}$ Garrett Hardin describes the destruction of commons (grazing land open for all local cattle herders to use) owing to individual herders grazing extra cattle at the expense of their community. If every herder takes the same approach, eventually the commons is completely overgrazed and useless to everyone.

The tragedy of the commons applies equally well to teaspoons. In the Burnet Institute the commons consists of a communally owned set of teaspoons; teaspoon users (consciously or otherwise) make decisions that their own utility is improved by removing a teaspoon for personal use, whereas everyone else's utility is reduced by only a fraction per head ("after all, there are plenty more spoons ..."). As more and more teaspoon users make the same decision, the teaspoon commons is eventually destroyed. The fact that teaspoons were lost significantly more rapidly from the Burnet Institute's communal tearooms (the "commons") compared with programme linked rooms, correlates neatly with Hardin's principle.

We propose a somewhat more speculative theory (with apologies to Douglas Adams and Veet Voojagig). Somewhere in the cosmos, along with all the planets inhabited by humanoids, reptiloids, walking treeoids, and superintelligent shades of the colour blue, a planet is entirely given over to spoon life-forms. Unattended spoons make their way to this planet, slipping away through space to a world where they enjoy a uniquely spoonoid lifestyle, responding to highly spoon oriented stimuli, and generally leading the spoon equivalent of the good life. ${ }^{4}$

Our data might also be contemplated through the prism of counterphenomenological resistentialism, which holds that les choses sont contre nous (things are against us). ${ }^{5}$ Resistentialism is the belief that inanimate objects have a natural antipathy towards humans, and therefore it is not people who control things but things that increasingly control people. Although it seems unreasonable to say that the teaspoons are exerting any influence over the Burnet Institute's employees (with the exception of the authors), their demonstrated ability to migrate and disappear shows that we have little or no control over them.

Future studies investigating the pattern of movement and loss of other types of cutlery or other equipment (perhaps even more expensive or important than teaspoons) could provide a broader picture of the phenomenon under study. Microchipping and satellite tracking systems would have enabled determination of the teaspoons' ultimate location (assuming they remained on planet Earth).

We have no reason to believe that beverage production or consumption or any other teaspoon related activities at the Burnet Institute are significantly different from that occurring at other medical research institutions, or indeed any other similar sized organisation; thus we believe our results are widely applicable.

\section{Conclusions}

The high level of dissatisfaction with teaspoon coverage identified in our follow-up survey shows that

\section{What is already known on this topic}

Information on the displacement of teaspoons in institutional settings is lacking in the medical and scientific literature

\section{What this study adds}

We lost nearly one teaspoon per 100 teaspoon days

People have no control over teaspoon migration; escape to a spoonoid planet and resistentialism are equally plausible explanations

teaspoons are an essential part of office life. Simultaneously, the rapid rate of teaspoon loss shows that their availability (and therefore office life) is under constant assault. Teaspoon displacement and loss leads to the use of forks, knives, and staplers to measure out coffee and sugar, inevitably causing a reduction in employee satisfaction; in addition, large amounts of time may be wasted searching for teaspoons, both factors leading to decreased employee efficiency. The cost of maintaining a workable teaspoon population, estimated at nearly $\$ A 100$ ( $£ 43 ; \$ 75$; €63) a year for the study setting alone, must also be considered. We recommend that new institutes design their facilities so that programme linked tearooms predominate over communal tearooms and that existing institutes consider renovations to reduce the risk of teaspoon loss. We also advise that buying teaspoons of higher quality has no economic benefit. Finally, we suggest that the development of effective control measures against the loss of teaspoons should be a priority on national research agendas.

We thank the employees of the Burnet Institute for their unwitting participation in this project and for the vigorous debate that followed its revelation (particularly Tony Stewart); those employees who were aware of the study and contributed to its design and conduct-Steve Wesselingh, Ian Cooke, Greg Battistella, and staff from the Centre for Epidemiology and Population Health Research; Andrew Symon for help with data collection, Jane Hocking for help with statistical analysis, Nick Crofts for introducing us to the delights of resistentialism, and WSM Summerskill for calling the biroid phenomenon to our attention.

Contributors: All authors contributed to the conception, design, and management of the study and to the preparation of the manuscript. MSCL collected the data, which were analysed by all authors. CKA is guarantor.

Competing interests: None declared.

Ethical approval: Our study was approved by the director of the Burnet Institute.

1 M Tech Nature Conservation, Tshwane University of Technology, Pretoria, South Afria. A preliminary assessment of the conservation status of marine turtles in Mozambique. wwwlists.ufl.edu/cgi-bin/wa?A2 = ind $0501 \& \mathrm{~L}=$ cturtle\& $\mathrm{F}=\& \mathrm{~S}=\& \mathrm{P}=10245$ (accessed 28 Jan 2005).

2 American Cetacean Society factsheet. Blue whale. www.acsonline.org/ factpack/bluewhl.htm (accessed 28 January 2005).

3 Hardin G. The tragedy of the commons. Science 1968;162:1243-8.

Adams D. The hitchhiker's guide to the galaxy. New York: Ballantine Books, 1979:320.

5 Jennings PE. Thingness of things. New York Times Magazine 13 Jun 1948:19-20.

(Accepted 9 October 2005) 